\title{
The Differences between Metaphor and Metonymy on the Cognitive Level and the Cases Study
}

Chu Yan , Shi Longfeng

English Department, Foreign Language School, North China Electric Power University, Baoding, Hebei, China

DOI: $10.36348 /$ sijll.2020.v03i03.002 $\quad$ |Received: 04.03.2020 | Accepted: 13.03.2020 | Published: 16.03 .2020

*Corresponding author: Chu Yan

\section{Abstract}

Cognitive metaphor and cognitive metonymy not only have modifying functions, but also are related to thinking. Cognitive linguistics holds that metaphor and metonymy are important means for us to expand our thinking. We can automatically and unconsciously obtain these modes of thinking metaphor and metonymy, and use metaphor and metonymy for thinking. From the perspective of cognitive linguistics, this paper explores two important ways of thinking: metonymy and metaphor, which are rooted in people's basic experience and constitute our daily thinking and action. Communication is restricted by the principles of information, economy, cognitive salience and social needs. The speaker either uses the knowledge structure in the source domain to highlight the knowledge structure in the target domain, that is, he uses metaphor, or chooses the highlighted and easily perceived part to replace the whole or other parts of the whole; and uses the whole with Gestalt perception to represent the information to be conveyed, that is, he uses metonymy to communicate. Therefore, the meaning beyond the discourse comes into being.

Keywords: Conceptual Metaphor; Conceptual Metonymy; Network Catchwords; Taboo.

Copyright @ 2020: This is an open-access article distributed under the terms of the Creative Commons Attribution license which permits unrestricted use, distribution, and reproduction in any medium for non-commercial use (NonCommercial, or CC-BY-NC) provided the original author and source are credited.

\section{INTRODUCTION}

According to Lakoff [1], cognitive model can be divided into metaphor model and metonymy model. Metaphorical pattern refers to projecting one proposition or image pattern onto the structure of another cognitive domain, which has a good explanatory power for conceptualization, understanding and reasoning of abstract things. Metonymy pattern is based on the metaphor pattern, which makes one component connect with another, transfers the part to the whole, and makes the part represent the whole. On the cognitive level, metaphor and metonymy are two means to expand the way of thinking and extend the meaning of words. Next, the paper analyzes the function of metaphor and metonymy in combination with the network catchwords and taboos.

\section{Conceptual Metaphor}

Lakoff \&amp; Johnson put forward the metaphor is not only a kind of language rhetoric, but also a way of thinking in their great work Metaphors We Live By [2]. He advocated that metaphor is the inherent characteristic of human conceptual system. It is not only a kind of thing at the language level, but also a kind of thing at the ideological level. The essence of metaphor is a kind of mapping relationship across different conceptual fields. This correspondence between entities in the two conceptual domains enables people to use the knowledge structure in the source domain to highlight the knowledge structure in the target domain. They pointed out the function of metaphor is "to enable us to understand another kind of thing from one kind of thing". Lakoff \&amp; Johnson divided the metaphor into three kinds: spatial metaphors, ontological metaphors, structural metaphors [2].

\section{Spatial Metaphors}

Spatial metaphor takes space as its origin domain, and gives the non spatial concept a spatial scope by projecting the spatial structure onto the non spatial concept. Such as:

Some priests, nuns and researchers spend a great deal of time shepherding or observing shopping---bag ladies and are doing what they can to better the life hermits who are down. (The Observer. April 9, 1978. Britain)

The basic research framework of cognitive linguistics is that the establishment of word meaning must refer to the encyclopedic concept content and human's interpretation of this content; the formation of 
concept is rooted in the universal experience, especially the spatial experience, which restricts the etaphorical construction of the psychological world. In the example, the conceptual metaphor is LESS IS DOWN, MORE IS UP. It is believed that this conceptual metaphor originates from some daily life experiences, which have a common structure: the correspondence between quantity and space: more correspondence, less correspondence. In this case, the source domain is our perception of patial cognition. DOWN expresses the meaning of lady hermits' low social status or low living standard.

\section{Ontological Metaphors}

Entity metaphor helps us to regard abstract events, activities and emotions as tangible entities and substances, which can undertake a series of functions such as reference, quantification, confirmation and goal setting. Such as:

Retired marine Colonel John V. Brennan contracted with the secretive arms dealer to sell Iraq \$181 million worth of uniforms. According to a lawsuit field last March, former Vice President Spiro Agnew served as an "intermediary" between the two. How much money did Agnew make in the deal? Soghnanlian, the dealer, says, "He did not go hungry."

The understanding of meaning is based on the conventionality of linguistic symbolic meaning or the rationality and experience of the interpreter. In the example, the source domain in the conceptual metaphor (DEAL IS MEAL) is "eating", the target domain is "arms trading", the knowledge structure of "eating" corresponds to the knowledge structure of "trading", the abstract concept of deal is concretized, and the cognitive domain of "eating" is systematically projected to the cognitive domain of "arms trading": there is no starvation, enough food and drink, and great profits. In the process of cognitive projection, the concept of "no starvation" is highlighted, while the kickbacks related to arms trade are not cheap, illegal and other things are actually covered up, thus weakening the semantics. This metaphor uses the experience of eating in daily life to understand and grasp the abstract and unspeakable concept of making money in a deal.

\section{Structural Metaphors}

The so-called structural metaphor is to construct another concept with fuzzy structure, vague definition or complete lack of internal structure through a clear and clearly defined concept. Both spatial metaphor and entity metaphor can be further developed into structural metaphor with richer content. Such as:

I met my waterloo in exam.

The metaphor EXAM IS WAR has two meanings: one is about the source of war, which is cruel, life and death, the military activity of competing wisdom and combat effectiveness of both sides; the other is about the target knowledge of examination, which is the scale of fierce competition, laborious, and testing your learning ability and teaching effect. This entity metaphor only extends the concept of exam, but if we extend this entity metaphor to the structural metaphor the exam is Waterloo, because the concept Waterloo used as the origin domain in the structural metaphor has a clear structure and definition, it is a famous key battle in the World War II period, ending in a tragic failure, and these are transplanted to the target domain through metaphor projection, so as the target domain, the exam also has a clear structure and definition. There is a similarity and analogy between the test and Waterloo. The battle of Waterloo is compared to the failure of the test, resulting in mapping. The speaker uses the example of Waterloo, a famous disastrous battle in history, to talk about the test experience and understatement the failure of an important test.

The cross domain conceptual mapping realized by metaphor is often the connection between role and value and the connection between an entity and its representation, which are based on similarity and analogy. Through experiential correlations, these metaphors based on similarity and analogy is mapped to the cognitive domain of "thinking". As a part of our conceptual system, this kind of metaphorical mapping has been fixed and become a shared and solidified way of concept formation. This knowledge will play a role in our on-line understanding of speech and become the input material for forming new metaphors or conceptual integration.

\section{Conceptual Metonymy}

Cognitive linguistics finds that metonymy is not a special rhetorical device, but a universal linguistic phenomenon, and it is also a basic way of thinking and behavior. According to Lakoff, metonymy is the representation of the whole or other parts of the whole in the same cognitive domain by the parts that are easy to perceive and understand [1]. In metonymy, metonymy serves as a reference point and can activate or provide a psychological channel to understand the target of metonymy. Langacker believes that metonymy can effectively coordinate two conflicting factors: one is that the speaker can make sure that the attention of the addressee is directed to the target he is referring to; the other is that we have a clear natural tendency to think and talk. There are a lot of Metonymy in vocabulary, sentence and discourse.

\section{Metonymy at the lexical level}

Metonymy is a typical single mapping. In a single mapping, a feature of the source domain is highlighted and mapped to a feature of the target domain. Highlighting a feature is consistent with the function of referential usage, so the target domain is 
conceptually enriched and the result has the potential of referential. Such as:

\section{He had five sandwiches and a quart of milk for} his snack.

This part represents the whole thing and is a typical referential metonymy at the lexical level. Here, the target domain contains the source domain, and this metonymy includes the expansion of the cognitive domain, that is to say, referring to a part of the cognitive domain, can fully activate the whole cognitive domain. There is a stronger metonymic relationship between the salient part and the whole category. The speaker uses "snacks" instead of "meals" to achieve the purpose of humor and satire.

\section{Metonymy at the sentence level}

Because of politeness, indirect speech acts are often used to express intention. Panther \&amp; Thornburg believed that indirect speech act is actually a metonymy. They think that speech act is actually the same as non-verbal act in our daily life, and the completion of both should have appropriate conditions and go through a certain stage. Indirect speech act should follow a metonymic rule, and the communicator often uses one speech act to substitute another. For example: Peter, a colleague who works in a large computer company, asked you to help complete an important design. You declined because of an appointment. Peter looked at the clock on the wall and replied:

\section{It is a good idea to finish a job.}

Peter is actually referring to the request: help us finish a job the content of speech is essentially influenced by the basic concept of metonymy. "The conceptual metonymy that the speaker wants the listener to do something is MOVEMENT / RESEASON FOR ACTION (wish of $S$ that $H$ performances an action for a lingual action)".

\section{Metonymy at the textual level}

Conversational implicature is also a metonymic phenomenon. For example, in the first scene of the second act of Shakespeare, Pandarus, Cressida\&\#39;s uncle, tries to persuade Cressida to marry Troilus instead of Hector, who always takes courtesy to Cressida. Here is their dialogue:

Pand: Well I say Troilus is Troilus.

Cress: Then you say as I say, for I am sure he is not Hector.

Pand: No, nor Hector is not Troilus in some degrees.

In fact, what is activated in category is a kind of typical properties. The conventional relation is the relation of things themselves, which is used by language expression. The conventional relation is embodied in the concrete content of implicit expression, which explains or complements the explicit expression of sentences, so that the discourse can be understood as a complete expression and ensures the progress of communication. In the example, literally, Troilus is Troilus does not provide any new information, but if we look at it from the perspective of the normal relationship in the category, under the specific context intervention, the sentence can be understood as: "Troilus is young" or "Troilus is valiant".

\section{The Relationship between Metaphor and Metonymy}

Whether it is to discuss metaphor or to study metonymy, it is necessary to study the relationship between them. Both metonymy and metaphor are conceptual, spontaneous and unconscious cognitive processes based on the original thinking mode and basic experience of the human brain. However, they are not arbitrary or random, but have their own justifications. They include conceptual mapping, can be regularized, and are important means to enrich language. In addition, both of them must rely on pragmatic reasoning, so that language expression and understanding can be more acceptable to people. At the same time, metonymy can help induce metaphor, and sometimes both can coexist in a sentence. For example, "sheep's head" (Human head like that of a sheep) refers to "stupid person". That is a metaphorical extension firstly, and then a metonymy.

\section{Inclusion View}

In the early stage of metaphor research, the conceptual category of metaphor is quite broad. Metonymy and other traditional figures of speech are usually regarded as the hyponymy of metaphor.

\section{The bipolar view of metaphor and Metonymy}

Jacobson published his famous paper "Two Aspects of Language and Two Types of Aphasia" in 1953. After the publication of this paper, metaphor and metonymy have always been associated with Jacobson's name. Jacobson's new connection to metaphor and metonymy stems from Saussure's two ways of arranging symbols in general linguistics, and develops this view in this field. He believes that choice and substitution are two aspects of the same process, so Jacobson's contribution is also to connect combination and proximity, and substitution and similarity. It is this series of relevance that enables us to call combination itself metonymic level and choice metaphoric level in linguistics.

\section{The connected system of Metaphor and Metonymy}

Radden believes that metonymy and metaphor defined by longitude can be regarded as the typical categories on both ends of "metonymy-metaphor continuum". Metonymy metaphor interaction belongs to the middle part of continuum axis. The difference between them is not discrete, but scalar. They are points on the continuum. This means that the nature of the conceptual relationship between two entities may approach one end depending on the angle of 
observation. In the process of metonymy's development to metaphor, there are two mechanisms, one is the experiential basis of metonymy, which restricts the choice of the source domain and its mapping, the other is the abstract mechanism. The level of abstraction affects how close a mapping is to one end. This abstract process is metonymic in itself. Such as: SADNESS IS DOWN.

In a word, Lakoff \&amp; Johnson discussed the concept of Metonymy in their great work Metaphor We Live By, pointing out that "metonymy concept" is the basis of people's thinking and behavior as well as "metaphor concept" [2]. The difference between metaphor and metonymy is obvious. Metaphor is based on the similarity of human association, and it occurs between two conceptual domains. Metonymy is based on adjacency association, which is the relationship between two entities in a conceptual domain. From the perspective of language ontology, cognitive linguistics studies metonymy, which is regarded as an important way of human thinking and an important means of human understanding of the objective world. Conceptual metonymy is the basis of human speech, thinking and action, which enables us to conceptualize related things. Like conceptual metaphor, conceptual metonymy is based on the common experience of human beings [2].

\section{The Specific Application of Metaphor and Metonymy in Internet Catchwords \\ The new, creative and curious language features of network catchwords and the use of a large number of metaphors and metonymies complement each other. Some forms of expression have new ideas and features, reflecting the characteristics of fresh and novel, convenient and fashionable, vivid and humorous, strong personalized color, etc. these features of network catchwords are inseparable from the use of a large number of metaphors and metonymies.}

\section{The application of metaphorical thinking mode in} network Catchwords

(1) I used to think I was a flower by the cliff, but later I knew it was just a piece of slag from the sea of people.

Metaphor: a flower

Noumenon: $m e$

Description of similarity: the garden and the self-esteem "I" (handsome man and beautiful woman) in the heart all have attractive appearance image, and are admired and admired by people, which are the embodiment of "beauty".

\section{Similar conceptual metaphors also include}

Wolf family: describe those netizens who often come and go in the Forum on their own, though they love beauty, but they don\&\#39;t cling to MM (Meimei).
Dinosaur: the ugly appearance of a prehistoric monster describes a girl who is not very good- looking

Landlord: the person who posts

House slaves: people who work all day to earn money to support their mortgage. Dwelling in a small space

Brick throwing: follow up

\section{Clapping bricks: criticizing some stickers}

Metaphor expresses the consistency of internal structure, internal relationship and logical relationship under cognitive mode. Metaphor is based on the similar association of things. Eighty five characteristics project from one domain (source domain) to another domain (target domain). Its main function is to realize the image and vivid description of abstract category.

\section{The application of metonymic thinking mode in network catchwords}

(1) "Curtilage man" and "curtilage woman" refer to those who don't go out without going out, as long as they can send food to the door and manage food. This is the slogan of "curtilage woman". These young beauties enjoy themselves when their families are closed. Most of the "house girls" are the only children born after the 1980s. They grow up in the eyes of their parents'love, and it is difficult to show themselves when they enter the society. So they look for a stage in the virtual world of the Internet. Then the concept of "otaku man" was introduced. House is just a space carrier of house men's and house women's life. It's just a part of their life that they can't leave home, and it's also the most prominent and easy to be perceived and remembered. With the characteristics of this part, it refers to the whole house men's and house women's life style of staying at home and indulging in network self entertainment, which is the formation of conceptual metonymy. So far, metonymy is considered as a cognitive tool for people to perceive the objective world.

\section{Similar Conceptual Metonymies Include}

If you save enough for $\$ 4.5$ and I save enough for $\$ 4.5$, we can go to the Civil Affairs Bureau to get married.

Use part (4.5) to refer to the whole (legal conditions of marriage registration-ID card, household register, cost of production, etc.).

Behind every successful Altman, there are a group of small monsters who are beaten in silence.

Use part (Altman, little monster) to refer to the whole (celebrities, ordinary people willing to contribute). 
Conceptual metaphor and metonymy are not only a rhetorical device in literary language, but also a powerful cognitive tool in conceptualized language usage system. Both of them are conceptual and are used for the formation of conceptualization of abstract categories; conceptual metaphor and metonymy are also automatic, unintentional and effortless, which are fixed and used by people in daily language communication; both of them are the expansion and development mode of language resources.

\section{Specific Application of Metaphor and Metonymy in Taboos \\ Application of metaphorical thinking mode in taboos}

Metaphor is a kind of psychological behavior, linguistic behavior and cultural custom of things that are perceived, imagined, understood and then perceived by implication. It is a linguistic phenomenon at first, and it means a deeper psychological phenomenon. The deep content of any cultural phenomenon is psychological phenomenon. The basic framework of metaphor is subject and vehicle. There are similarities between metaphor and ontology. Its structure can be seen as "A as B" or "A is B". In "passion as fire", passion is ontology and fire is metaphor. Metaphor takes fire as an entity to understand the abstract meaning of passion. Therefore, we can say that metaphor is to understand another thing through one thing.

Taboo usually highlights some important features, hides some features of the source domain, and projects them to the target domain. In fact, by combining euphemism and metaphor, it is through conceptual metaphor that the source domain (euphemism) is systematically projected to the target domain (taboo). Because the systematic nature of projection can highlight those pleasant parts and hide those unpleasant, embarrassing and shameful aspects.

For example, in both the eastern and Western societies, "death" is a hidden topic. This is because human beings are facing the same objective world. Our understanding of the objective world comes from our experience of our body and daily life experience. People's ideas and cognitive experience show many common characteristics. Therefore, in both Chinese and English expressions, we usually don't say "he died". On the contrary, we will use some indirect expressions of euphemism. There are many similarities in Chinese and English euphemisms about death.

Such as: "LIFE IS A JOURNEY, DEATH IS THE END OF THE JOURNEY BUT THE START OF ANOTHER JOURNEY", that is, "LIFE IS A JOURNEY", in the metaphor, "DEATH" is the end of the journey and the start of the journey. In this domain of concepts, there are corresponding idioms in English: "depart this life", "depart out of this world" , "depart from the world forever", "leave the land of the living", "go to/reach a better world", "go out", go to heaven".

There are also in Chinese: gone, past, left, farewell, back home, to another world, etc.

In both languages, people see "death" as the end of a journey, but at the same time, people express good hope: "death" is the beginning of another journey. This reflects the commonness of human cognition. All human beings have a common cultural core. The source domain of life is mapped to the target domain, which makes it easier for people to understand the process of life and produce more vivid concepts in the human brain. In this metaphor, birth is the beginning of the journey of life, each age of life corresponds to each stage of the journey, and the end of the journey is the end of life-death.

\section{Application of metonymic thinking mode in taboos}

Conceptual metonymy, like conceptual metaphor, is based on human common experience. The mapping of experience or conceptual structure in the same field constitutes metonymy. Metonymy is a mapping between two cognitive domains, which is characterized by its proximity and significance. For example, "Shakespeare is my favorite" here refers to the works of this great writer, not himself. Some metonymic words with high frequency have been widely accepted and included in the dictionary, such as "hand" in "we needs more hands in the harvest time".

Metonymy is not a special linguistic phenomenon, and it is not only a linguistic phenomenon, but also a conceptual phenomenon that can organize people's thoughts and behaviors. Lakoff [2] uses the example of "She is just a pretty face" to explain the nature of Conceptual

Metonymy: if someone uses this sentence to evaluate his secretary, we can see that he highlights a person's explicit aspect (face) in the use of language to convey the overall content of information.

Metonymy is an ideal target, which can provide a reference point for psychological accessibility. In the cognitive process of metonymy, ontology, as a conceptual entity, provides psychological accessibility for another conceptual entity in the same idealized cognitive model.

Taboo as a language symbol. Although its prototype can\&\#39;t appear in communication, it doesn't mean that language symbols like it won\&\#39; appear. It will appear in different ways of anaphora. 


\section{CONCLUSION}

Metaphor and metonymy are the basic cognitive mechanisms of human beings. The language of metaphor and metonymy deeply reflects the organization of cognition. Metaphor and metonymy are not only the important mechanism of human cognition, but also the basis of people's conceptualization. Evans \&amp; Green [3], metaphor and metonymy are the way of human existence, the primary and basic way of thinking, not just the expression of words.

Metaphor is the projection of words expressing concepts from a source domain to a target domain. Target domain is a spatial domain which has meaning but has no word expression form, so it needs to borrow words from the source domain to express, so the mapping phenomenon of cognitive domain occurs, that is, the starting point of the source domain will map to the starting point of the target domain, the target of the source domain will map to the target domain, and the result is the mapping of one concept domain to another concept. The meaning of metaphor is to map some features of things in the source domain to the target domain. Metaphor is ubiquitous in our daily life. It exists in language, thinking and philosophy. It is difficult to think without metaphor. Metaphor is the most basic way for human beings to understand the world, and it is the common feature of human thinking. It exists in all cultures in the world and is the basis of most languages.

The most essential feature of metonymy is that it establishes the substitute relationship between things by means of their relevance or proximity. Between the two interrelated things, there is the foundation of metonymy. There are several kinds of relevance or contiguity: the interrelationship or adjacent relationship between the whole and the parts, and the interrelationship or adjacent relationship between the parts of the same thing.

Metonymy and metaphor is a psychological mechanism in cognitive linguistics, which has become the basis of many human concepts: ambiguity and clarity, pleasure and unhappiness, civilization and rudeness.

\section{REFERENCES}

1. Lakoff, G. (1987). Image metaphors. Metaphor and Symbol, 2(3), 219-222.

2. Lakoff, G., \& Johnson, M. (2003). Metaphors we live by. 1980. Uniiversity of Chicago Press.

3. Evans, V. (2006). \&amp; M. Green. Cognitive Linguistics: An Introduction. 